been much improved by the introduction of single photon emission tomography. In one study planar imaging had a sensitivity of $73 \%$ and a specificity of $50 \%$ whereas single photon tomography produced values of $80 \%$ and $75 \%$ respectively. ${ }^{7}$ The posterior aspects of the heart are poorly visualised with the planar technique as sensitivity is low for lesions of the left circumflex artery. Although tomography requires an expensive gammacamera and computing facility, it can also be used for other, non-cardiac forms of nuclear imaging.

The quality of information from perfusion imaging is limited by patients' ability to exercise and increase their coronary artery blood flow. A poor heart rate response to stress greatly reduces the accuracy of this test, ${ }^{8}$ although pharmacological stressors to increase coronary blood flow, such as intravenous dipyridamole, adenosine, or dobutamine, may be used in such patients.

Perfusion imaging is particularly useful in patients with an equivocal electrocardiographic response to exercise testing who require further non-invasive assessment. The addition of thallium imaging improves the sensitivity of exercise electrocardiography from $68 \%$ to $89 \%$ and the specificity from $77 \%$ to $89 \%$. $^{9}$ Information can also be obtained in patients with electrocardiographic abnormalities at rest, such as left bundle branch block, left ventricular hypertrophy, and those due to digoxin, in whom interpretation of an exercise test is unreliable. This test may be used to identify the most important coronary artery stenosis for angioplasty in patients with multivessel disease. Lastly, physical disability may prevent the use of exercise testing to assess chest pain but does not preclude use of pharmacological stress for myocardial perfusion imaging. Although thallium-201 is still used most commonly, the more expensive technetium-99m methoxy isobutyl isonitrile with its better imaging qualities and lower radiation dose is being used more often; reports suggest a better sensitivity with technetium than thallium. ${ }^{10}$

Myocardial viability can be assessed by using radiolabelled metabolic substrates with positron emission tomography. Few places offer this type of imaging, but thallium-201 has been used as an alternative. ${ }^{11}$ Patients with suspected myocardial infarction rarely require radionuclide imaging with infarct avid agents such as technetium-99m pyrophosphate or antibodies to myosin labelled with indium-111 to confirm the diagnosis, but these agents are helpful in some patients who have an atypical cardiac enzyme response or non-diagnostic electrocardiographic findings or who have had cardiopulmonary resuscitation with cardioversion.

Radionuclide investigations in cardiology should be used to supplement or complement information from electrocardiography and echocardiography. They are useful in selecting patients for tertiary referral. Provided the hospital uses the imaging device for all nuclear imaging, the cost of individual cardiac investigations is relatively cheap compared with cardiac catheterisation. The tests are probably best performed under the combined direction of a specialist in nuclear medicine and a cardiologist as this ensures the important marriage of clinical information with the patient's images. All regional cardiac centres have access to these types of investigation. The finding that only half of the health districts in England and Wales perform cardiac radionuclide investigation suggests that it probably is an underused facility.

ALLISTER HARGREAVES Lecturer in Medicine

ALEXANDER L MUIR Postgraduate Dean

Department of Medicine, Edinburgh Post Graduate Board for Medicine

Royal Infirmary,

Edinburgh EH3 9YW

1 Chamberlain D, Pentecost B, Reval K, Stevens J, Boyle DM, Cobbe S, et al. Staffing in cardiolog in United Kingdom 1990. Sixth Biennial survey: with data on facilities in cardiology in England and Wales 1989. Br Heart $f$ 1991;66:395-404.

2 Underwood R, Gibson C, Tweddel A, Funt J on behalf of the British Nuclear Cardiology Group. A survey of nuclear cardiological practice in Great Britain. Br Heart $\mathcal{F}$ 1992; 67:273-7.

3 Goldman L, Feinstein AR, Batsford WP, Cohen LS, Gottschalk A, Zaret BL. Ordering patterns and clinical impact of cardiovascular nuclear medicine procedures. Circulation 1980;62:680-7. 4 Goldman L, Cohn PF, Mudge GH, Hashimoto B, Sherman H, Wynne J, et al. Clinical utility and management impact of M-mode echocardiography. Am f Med 1983;75:49-56.

5 Hammermeister KE, DeRouen TA, Dodge HT. Variables predictive of survival in patients with coronary artery disease. Selection by univariate and multivariate analyses from the clinical, electrocardiographic, exercise, arteriographic, and quantitative angiographic evaluations. Circulation 1979;59:421-30.

6 Dewhurst NG, Muir AL. Comparative prognostic value of radionuclide ventriculography at rest and during exercise in 100 patients after first myocardial infarction. Br Heart $\mathcal{F}$ 1983;49:111-21.

Kahn JK, McGhie I, Akers MS, Sills MN, Faber TL, Kulkarni PV, et al. Quantitative rotational tomograrhy with ${ }^{2 w} \mathrm{Tl}$ and ${ }^{{ }^{4} \mathrm{~T}} \mathrm{Tc} 2$-methoxyisobutyl-isonitrile: a direct comparison in normal individuals and patients with coronary artery disease. Circulation 1989;79:1282-93.

8 McLaughlin PR, Martin RP, Doherty P, Daspit S, Goris M, Haskell W, et al. Reproducility of thallium-201 myocardial imaging. Circulation 1977;55:497-503.

Beller GA, Diagnostic accuracy of thallium-201 myocardial perfusion imaging. Circulation 1991;84 (suppl I): 1-6.

10 Kiat H, Maddahi J, Roy LT, Van Train K, Friedman J, Resser K, et al. Comparison of technetium $99 \mathrm{~m}$ methoxy isobutyl isonitrile and thallium 201 for evaluation of coronary artery disease by planar and tomographic methods. Am Heart $\mathcal{F}$ 1989;117:1-11.

11 Dilsizian V, Rocco TP, Freedman NMT, Leon MB, Bonow RO. Enhanced detection of ischemic but viable myocardium by the reinjection of thallium after stress-redistribution imaging. $N$ Eng f Med 1990;323:141-6.

\title{
Cancer chemotherapy and quality of life
}

\section{Cancer trials should include measures of patients' wellbeing}

When a cure of advanced cancer is a realistic prospect both patient and doctor seem willing to accept the toxicity associated with chemotherapy. Patients with Hodgkin's disease, high grade non-Hodgkin's lymphoma, or metastatic testicular tumours rarely reject the offer of chemotherapy because of concern about their quality of life during treatment. The hope of cure is weighed against the certainty of death and the choice clarifies the issue. Chemotherapy may also be offered, however, as treatment for advanced cancers of the gastrointestinal tract, lung, or breast - in which the prospect of cure is slight. In these circumstances a decision for or against treatment must be based on the probability of achieving palliation.
By definition, palliative chemotherapy ought to improve the quality of life of a patient with cancer; yet evidence that it does so is often difficult to find. End points indicating quality of life have rarely been included in the assessment of outcome in clinical trials. ${ }^{12}$ The traditional end points are survival, disease free survival, tumour response rate, and duration of response. Even where accompanied by data on toxicity those results are often inadequate to answer the question "Will I be better off if I have the treatment?" That is the question the patient wants answered, and the doctor is expected to help in this judgment; but judgments vary and are particularly likely to do so when based on information somewhat removed from the main question. As Pope indicated, "'tis with our 
judgments as our watches, none go just alike yet each believes his own."

On those few occasions when quality of life or effectiveness of palliation is assessed in clinical trials the results can be very instructive. The Australian-New Zealand Breast Cancer Trials Group tested the hypothesis that in metastatic breast cancer intermittent chemotherapy might provide better palliation than continuous chemotherapy. ${ }^{3}$ It didn't. One group of patients was randomised to receive chemotherapy until the disease progressed. Others received three cycles of the treatment and restarted it only when the disease progressed. During the first three cycles, when both groups were receiving identical treatment, the patients' quality of life improved substantially. Nausea and vomiting were more pronounced during chemotherapy, but the patients' own assessment of their physical wellbeing, pain, mood, appetite, and overall quality of life all improved. Other non-specific symptomatic care was available to the patients and may have accounted for some of the benefit, but this result suggested an improvement in quality of life due to chemotherapy.

After three cycles one group continued chemotherapy with its attendant toxicities while the other had no specific antitumour treatment. Those given continuous chemotherapy reported a superior quality of life. These two results taken together strongly support the palliative value of chemotherapy in advanced breast cancer.

Chemotherapy may improve survival for patients with advanced colorectal cancer ${ }^{+}$and with non-small cell lung cancer. ${ }^{5}$ Mackillop et al, however, found that over four fifths of experts on lung cancer would refuse to be enrolled in a trial of chemotherapy if they had metastatic non-small cell lung cancer. ${ }^{6}$ The main reasons for rejecting the treatment were its toxicity and its perceived ineffectiveness.

In most branches of medicine perceptions of the value of treatment may vary widely depending on who is asked. Jachuck et al found that all doctors thought that their patients' quality of life had improved after they started antihypertensive treatment but that three quarters of the patients' relatives thought that it was worse. ${ }^{7}$ When the patients were interviewed $48 \%$ said that they felt better, $8 \%$ felt worse, and $44 \%$ felt the same. Whose was the correct perception? Surely those on the receiving end.

The use of chemotherapy in conjunction with definitive local treatment with curative intent-so called adjuvant chemotherapy - can produce substantial improvements in disease free and overall survival in cancers of the breast, ${ }^{8}$ colon, ${ }^{9}$ and rectum..$^{10}$ Of women interviewed after they had received adjuvant chemotherapy for early breast cancer, $46 \%$ thought that the inconvenience and toxicity of the treatment was worth while if they gained as little as six months' improvement in a life expectancy of five years. More than half thought a $2 \%$ improvement, from $65 \%$ to $67 \%$, in their chances of living five years was enough to justify treatment. ${ }^{\prime \prime}$ Adjuvant treatment with combined cyclophosphamide, methotrexate, and fluorouracil (CMF) improves the five year survival of women under 50 with node positive breast cancer by about $10 \% .^{12}$ This amount of benefit seems to be of sufficient size to justify the costs in the minds of the recipients, explaining the widespread acceptance of adjuvant chemotherapy in this setting.

The place of adjuvant chemotherapy in the treatment of stage I breast cancer, which has an excellent prognosis with surgery alone, is highly contentious. ${ }^{13}{ }^{14}$ Innovative techniques have been used to take account of the time a patient may spend with, on the one hand, toxicity due to treatment and, on the other, recurrent disease. ${ }^{15}$ Nowadays assessments of quality of life are part of the evaluation of patients during trials of adjuvant therapy, ${ }^{16}$ and these methods should be especially valuable in analysing benefit in stage I disease.

If, as seems likely, the benefit of new adjuvant treatments is limited and is of the order already achieved, the impact on quality of life may well be the basis of choice between such treatments in the coming decade. Patients with incurable cancer will accept the offer of chemotherapy more readily if they can be assured that the quality of life of others in similar circumstances has been improved by such treatment. The more widespread use and critical evaluation of the instruments employed to assess quality of life in trials of adjuvant and palliative chemotherapy now being undertaken are to be welcomed. ${ }^{216-18}$

Head of Department,

MICHAEL BYRNE

Department of Medical Oncology,

Sir Charles Gairdner Hospital,

Queen Elizabeth II Medical Centre,

Nedlands,

Western Australia 6009

1 Clark A, Fallowfield LJ. Quality of life measurements in patients with malignant disease: a review. IR Soc Med 1986;79:165-9.

2 Donovan K, Sanson-Fisher RW, Redman S. Measuring quality of life in cancer patients. $\mathcal{F}$ Cli Oncol 1989;7:959-68.

3 Coates A, Gebski V, Bishop J, Jeal PN, Woods RL, Snyder R, et al. Improving the quality of life during chemotherapy for advanced breast cancer. A comparison of intermittent and continuous treatment strategies. N Engl f Med 1987;317:1490-5.

4 Poon MA, O'Connell MJ, Moertel CG, Wieand HS, Cullinan SA, Everson LK, et al. Biochemica modulation of fluorouracil: evidence of significant inprovement of survival and quality of life in patients with advanced colorectal carcinoma. $\mathcal{F}$ Clin Oncol 1989;7:1407-17.

5 Rapp E, Pater JL, Willan A, Cormler Y, Murray N, Evans WK, et al. Chemotherapy can prolong survival in patients with advanced non-small-cell lung cancer: report of a Canadian multicenter survival in patients with advanced non-small
randomized trial. $\mathcal{F}$ Clin Oncol 1988;6:633-41.

6 MacKillop WJ, W'ard GK, O'Sullivan B. The use of expert surrogates to evaluate clinical trials in non-small cell lung cancer. Br $\mathcal{Y}$ Cancer 1986;54:661-7.

7 Jachuck SJ, Brierley H, Jachuck S, Willcox PM. The effect of hypotensive drugs on the quality of life. $7 R$ Coll Gen Pract 1982;32:103-5.

8 Early Breast Cancer Trialists' Collaborative Group. Systemic treatment of early breast cancer by hormonal, cytotoxic or immune therapy: 133 randomised trials involving 31,000 recurrences an 24,000 deaths among 75,000 women. Lancet 1992;339:1-15,71-85.

9 Moertel CG, Fleming TR, MacDonald JS, Haller DG, Laurie JA, Goodman PJ, et al. Levamisole and fluorouracil for adjuvant therapy of resected colon carcinoma. $N$ Englf Med 1990;322:352-8.

10 Krook JE, Moertel CG, Gunderson LL, Wieand HS, Collins RT, Beart RW. Effective surgica adjuvant therapy for high risk rectal carcinoma. $N$ Englf Med 1991;324:709-15.

11 Coates AS, Simes RJ. Patient assessment of adjuvant treatment in operable breast cancer. In: Williams CJ, ed. Introducing new treatments for cancer: practical, ethical and legal problems. London: John Wiley, 1992:447-58.

12 Early Breast Cancer Trialists' Collaborative Group. Treatment of early breast cancer. Vol 1. Worldwide evidence 1985-1990. Oxford: Oxford University Press, 1990:65-8.

13 McGuire WL. Adjuvant therapy of node-negative breast cancer. $N$ Engl f Med 1989;320:525-7.

14 DeVita VT. Breast cancer therapy: Exercising all our options. N Engl f Med 1989;320:527-9.

15 Goldhirsch A, Gelber RD, Simes J, Glasziou P, Coates AS. Cost and benefits of adjuvant therapy in breast cancer: a quality-adjusted survival analysis. 7 Clin Oncol 1989;7:36-44.

16 Hurny C, Bernhard J, Gelbert R, Coates AS, Castiglione M, Isley M, et al. Application of quality of life measures for breast cancer patients in an international trial: the IBCSG experience. I. Compliance, impact of time, language and treatment. Eurf Cancer (in press)

17 McMillen Moinpour C, Feigl P, Metch B, Hayden KA, Meyskens FL, Crowley J. Quality of life endpoints in cancer clinical trials: review and recommendations. $\mathcal{I}$ Natl Cancer Ins 1989;81:485-95.

18 Butow P, Coates A, Dunn S, Bernhard J, Hurny C. On the receiving end. IV. Validation of quality of life indicators. Annals of Oncology 1991;2:597-603.

\section{Corrections}

\section{The road to Rio}

An editorial error occurred in this article by Sir Donald Acheson (30 May, p 1391). The reference cited in the fourth paragraph should have been: Report of the WHO Commission on Health and the Environment. Summary. Our Planet, Our Health. Geneva: WHO, 1992

\section{A meeting of rich and poor}

An authors' error occurred in this editorial by Richard Smith and Robin Stot (30 May, pp 1392-3). The second sentence of the third paragraph should have read: In 1990 the developing countries received $£ 28.3$ billion in aid but had to pay back $£ 34.5$ billion in interest on their debts. 